\title{
A randomised double-blind clinical trial of acyclovir (Zovirax) and adenine arabinoside in herpes simplex corneal ulceration
}

\author{
B. J. YOUNG, ' A. PATTERSON,' AND T. RAVENSCROFT ${ }^{2}$ \\ From 'St Paul's Eye Hospital, Liverpool, and the ${ }^{2}$ Wellcome Research Laboratories, Beckenham, Kent
}

SUMmARY A double-blind clinical trial of 3\% acyclovir (Zovirax) and 3\% adenosine arabinoside (ara-A, Vidarabine) in 93 patients with herpetic corneal ulceration is presented. Ulcers in $45(94 \%)$ of acyclovir-treated patients and $37(82 \%)$ ara-A-treated patients healed within 14 days. Patients treated with acyclovir healed more rapidly than those treated with ara-A $(p<0 \cdot 01)$. No serious adverse effects were observed.

Acyclovir (Zovirax) is a potent and selective antiherpes virus agent when it is phosphorylated into its active form by a virus specified thymidine kinase. ${ }^{12}$

Initial evidence of action against human herpes simplex infections was obtained by Jones et $^{a l} .^{3}$ in 1979. Subsequently double-blind studies of its use in herpetic corneal ulceration have shown acyclovir to be at least as effective as idoxuridine (IDU) ${ }^{45}$ or trifluorothymidine (F3T). ${ }^{6}$

Adenosine arabinoside (ara-A) was first synthesised in 1960 as an anticancer agent and originally investigated with this application in mind. ${ }^{7}$ In herpetic corneal ulceration ara- $\mathrm{A}$ is as effective as IDU $^{8}$ and F3T. ${ }^{9}$ This report describes a double-blind clinical trial comparing acyclovir with adenosine arabinoside in herpetic keratitis.

\section{Patients and methods}

The patients included in this study, seen at St Paul's Eye Hospital, Liverpool, were diagnosed clinically as having herpetic corneal disease by slit-lamp biomicroscopy subsequent to staining with rose Bengal. At the initial visit corneal swabs were taken from all patients for culture of herpes simplex virus in Vero cells at $35^{\circ} \mathrm{C}$. Patients excluded from the trial were those who were less than 16 years of age, were pregnant, had a corrected visual acuity of $6 / 24$ or worse in the contralateral eye, were unable to attend regularly for follow-up, or had received other antiviral medication for their current attack. Full ocular

Correspondence to Mr B. J. Young, St Paul's Eye Hospital, Old Hall Street, Liverpool L3 9PF. examinations were carried out at presentation and during follow-up assessments by one of 2 ophthalmologists. When possible a given patient was assessed by the same observer. Assessment of efficacy was planned for days $2,4,6,8,11$, and 14 of treatment. Patients were required to fill in cards to record their use of the ophthalmic ointment.

Treatment with either $3 \%$ acyclovir or $3 \%$ ara-A 5 times daily was assigned randomly to patients. The ophthalmic ointments were provided in identical tubes bearing a trial number, and the entire study was carried out in a double-blind manner. Therapy was continued at least until the epithelial defect had healed. If the ulcer increased significantly in size over 3 days, remained static for 7 days, or had failed to heal within 14 days, the patient was crossed over, under the direction of the chief pharmacist, to the alternative medication. Patients already receiving local steroids at presentation and those presenting with amoeboid ulceration were included in the study, but separate consideration was given to them in the analysis of results.

If any patient's ulcer reappeared at the same site within 14 days of stopping therapy, it was designated a recrudescent ulcer and was treated with the alternative trial drug. Ulcers appearing after 14 days were designated recurrent ulcers and were treated with the same coded antiviral treatment. Patients were reviewed 6 months after therapy was terminated.

\section{Results}

Forty-five patients received ara-A and 48 patients received acyclovir ophthalmic ointment. The 
Table 1 Distribution of patients according to ulcer type

\begin{tabular}{lll}
\hline Ulcer & Acyclovir & Ara-A \\
\hline Simple dendritic & 40 & 39 \\
Steroid treated dendritic & 2 & 4 \\
Amoeboid & 6 & 2 \\
\hline
\end{tabular}

Table 2 Patients' characteristics at presentation

\begin{tabular}{|c|c|c|}
\hline $\begin{array}{l}\text { Patients' } \\
\text { characteristics }\end{array}$ & Acyclovir & Ara $-A$ \\
\hline Sex: male & 32 & 30 \\
\hline female & 16 & 15 \\
\hline Average age & 51 & 52 \\
\hline \multicolumn{3}{|c|}{ Duration of symptoms: } \\
\hline 1 week or less & 39 & 37 \\
\hline $2-3$ weeks & 5 & 6 \\
\hline 4 weeks or greater & 4 & 2 \\
\hline \multicolumn{3}{|l|}{ Ulcer size: } \\
\hline large & $\begin{array}{l}\text { dendritic } 16(38 \%) \\
\text { amoeboid } 3\end{array}$ & $\begin{array}{l}\text { dendritic } 19(44 \%) \\
\text { amoeboid } 1\end{array}$ \\
\hline $\begin{array}{l}\text { multiple small } \\
\text { small }\end{array}$ & $\begin{array}{l}\text { dendritic } 13(31 \%) \\
\text { dendritic } 13(31 \%)\end{array}$ & $\begin{array}{l}\text { dendritic } 10(23 \%) \\
\text { dendritic } 14(33 \%) \\
\text { amoeboid }\end{array}$ \\
\hline \multicolumn{3}{|l|}{$\begin{array}{l}\text { History of cutaneous } \\
\text { herpes }\end{array}$} \\
\hline (\% of patients) & $42 \%$ & $42 \%$ \\
\hline $\begin{array}{l}\text { Primary ocular } \\
\text { infection } \\
\text { Recurrent ocular }\end{array}$ & $35 \%$ & $59 \%$ \\
\hline infection & $65 \%$ & $41 \%$ \\
\hline
\end{tabular}

numbers of patients presenting with each type of ulcer are given in Table 1.

Before the significance of the results was assessed it was important to establish that the groups of patients were similar, especially with respect to factors likely to affect healing rate. The groups were well matched in terms of sex, age, duration of symptoms before presentation, and ulcer size at presentation. There was no significant difference in the numbers presenting with initial or recurrent attacks $(p<0 \cdot 05$, Fisher's exact test, $\left.\chi^{2}=3 \cdot 101\right)$. The data are presented in Table 2. Patient compliance as indicated by their diary cards was $94 \%$ in the acyclovir group and $95 \%$ in the ara-A group. Laboratory confirmation of the diagnosis by culture from corneal swabs was positive in $38 \%$ of cases.

In the acyclovir-treated group 3 ulcers failed to heal. One patient aged 74 years who had symptoms for 4 weeks presented with 2 large dendritic ulcers from which herpes simplex virus was isolated. The ulcers remained active after 14 days and resolved after a 10-day course of ara-A. The second patient, receiving steroids at entry, had a large dendritic ulcer which responded poorly to both antiviral agents; he was admitted and removed from the trial on day 26 because of increasing stromal infiltration.
The third patient aged 74 presented with a large amoeboid ulcer on a 6-month-old corneal graft. The ulcer was designated cured on day 14 but recurred 3 weeks later and responded unsatisfactorily to acyclovir. In the ara-A group 8 patients failed to respond satisfactorily to therapy. Seven of the ulcers were simple dendritic and one was an amoeboid ulcer. Five of the dendritic ulcers and the amoeboid ulcer were treated with acyclovir and all healed in an average of 7 days (range 4-12 days).

The time to complete healing for all patients ranged from 2 to 14 days. A logrank analysis was performed on the healing time data for acyclovir and ara- $A$, and a significant difference was found in favour of acyclovir $(p<0 \cdot 01)$. This level of significance was achieved when the dendritic ulcers were considered alone and when all ulcers were considered as a group. A graph representing the cumulative healing rate for dendritic ulcers is presented in Fig. 1.

Two patients with amoeboid ulcers were entered into the ara-A group. A large ulcer failed to heal, while a small ulcer healed in 6 days. Six amoeboid ulcers were treated with acyclovir and five healed in

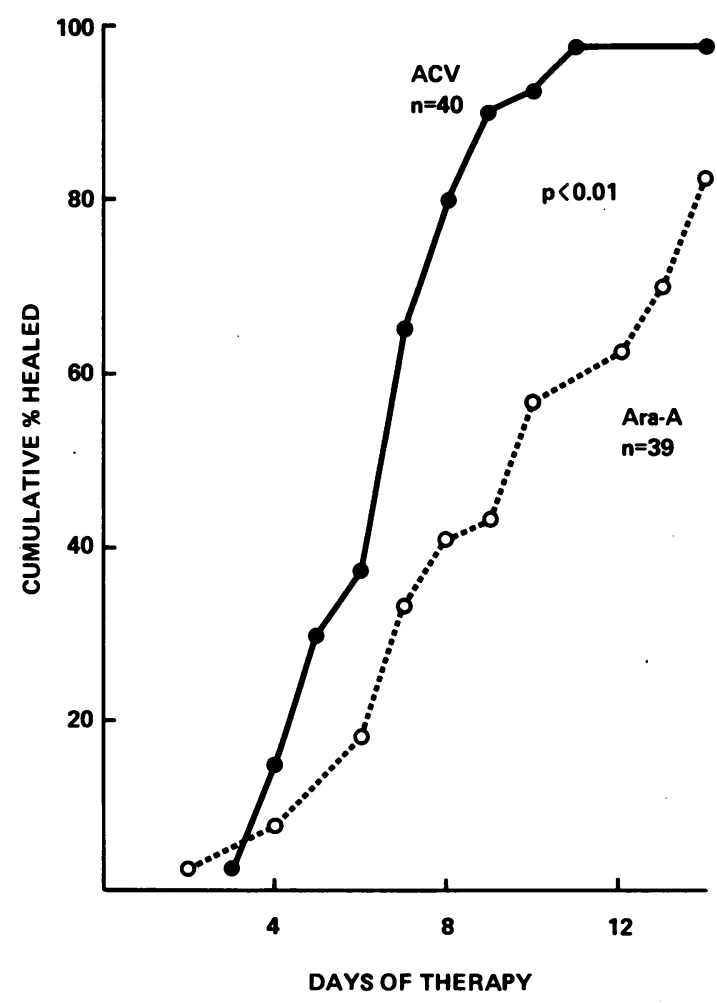

Fig. 1 Cumulative frequency distribution of percentage healing rate for patients with dendritic ulcers treated with acyclovir $(A C V)$ and adenine arabinoside (ara-A). 
Table 3 Response to therapy according to ulcer size and type

\begin{tabular}{llllcl}
\hline Ulcer & Size & $\begin{array}{l}\text { Acyclovir } \\
\text { mean } \\
\text { healing time } \\
\text { (days) }\end{array}$ & Failed & $\begin{array}{l}\text { Ara-A } \\
\text { mean } \\
\text { healing time } \\
\text { (days) }\end{array}$ & Failed \\
\hline Dendritic: & small & $6 \cdot 2$ & - & $8 \cdot 5$ & - \\
& multiple & $6 \cdot 2$ & - & $8 \cdot 5$ & 2 \\
Amoeboid: & large & $7 \cdot 5$ & 2 & $10 \cdot 5$ & 6 \\
& small & $6 \cdot 0$ & - & $6 \cdot 0$ & - \\
& large & $8 \cdot 0$ & 1 & - & 1 \\
\hline
\end{tabular}

an average of 6.6 days. Of 3 large ulcers, one failed to heal and 2 healed in an average of 8 days. Of the 3 small ulcers all healed in an average of 6 days. This group was too small and unbalanced to carry out further analysis. Table 3 shows the average healing times for each category of ulcer treated in the study and indicates the distribution of treatment failures among these groups.

Two patients developed adverse symptoms during therapy possibly due to their antiviral therapy. One patient on acyclovir experienced an allergic response; this could also have been caused by the atropine drops being administered concurrently. One patient on ara-A complained of grittiness after application of the ointment. No other adverse effect was seen in this group of patients.

\section{Discussion}

Acyclovir and ara-A were found to be effective agents for the treatment of dendritic ulceration, and ulcers treated with acyclovir healed more rapidly. As expected, the larger ulcers took longer to heal in both groups and constituted most of the treatment failures. The amoeboid ulcer groups were too small to analyse separately but were less of a problem than during the previous series carried out at this hospital, ${ }^{9}$ possibly due to more awareness among general practitioners of steroid-induced complications. Most ulcers responded within 2 weeks and the remainder were given alternative therapy after this time. The incidence of adverse side effects during this relatively short exposure to acyclovir and ara-A was low. One patient on acyclovir experienced an allergic response which might have been due to other concurrent medication. One patient on ara-A complained of grittiness of the eye after application of the ointment.
A number of antiviral agents have been found to be effective in treating dendritic ulceration, but acyclovir is apparently superior in providing more rapid healing. A similar study ${ }^{10}$ comparing acyclovir with ara-A showed a faster healing rate for acyclovir, which did not reach statistical significance. This may have been due to the smaller number of patients included and the larger proportion of small ulcers in the ara-A group, which tend to heal more rapidly.

The need for a potent nontoxic antiviral agent which can be used for long periods in deep corneal disease is obvious. The fact that $3 \%$ acyclovir ointment penetrates into the anterior chamber in therapeutic levels ${ }^{11}$ and has been used systemically to clear a hypopyon in advanced herpetic corneal disease $^{12}$ indicates its promise in patients who manifest recalcitrant ulceration and keratouveitis.

\section{References}

1 Elion GB, Furman PA, Fyfe JA, et al. Selectivity of action of an antiherpetic agent, 9-(2-hydroxyethoxymethyl)guanine. Proc Natl Acad Sci USA 1977; 74: 5716-20.

2 Fyfe JA, Keller PM, Furman PA, et al. Thymdine kinase from herpes simplex virus phosphorylates the new antiviral compound 9-(2-hydroxyethoxymethyl)guanine. J Biol Chem 1978; 253: 8721-7.

3 Jones BR, Coster DJ, Fison PN, et al. Efficacy of acycloguanosine (Wellcome $248 \mathrm{U}$ ) against Herpes simplex corneal ulcers. Lancet 1979; i: 243-4.

4 Coster DJ, Wihelmus KR, Michaud R, Jones BR. A comparison of acyclovir and idoxuridine as treatment for ulcerative herpetic keratitis. Br J Ophthalmol 1980; 64: 763-5.

5 Collum LMT, Benedict-Smith A, Hillary IB. Randomised double-blind trial of acyclovir and idoxuridine in dendritic corneal ulceration. Br J Ophthalmol 1980; 64: 766-9.

6 La Lau C, Oosterhuis JA, Versteeg G, et al. Acyclovir and trifluorothymidine in herpetic keratitis: preliminary report of a multicentre trial. Doc Ophthalmol 1981; 50: 287-90.

7 Brink JJ, LePage GA. 9-B-D-arabinofuranosyladenine as an inhibitor of metabolism in normal and neoplastic cells. Can $J$ Biochem 1965; 43: 1-15.

8 Pavan-Langston D, Dohlman CH. A double blind clinical study of adenine arabinoside therapy of viral keratoconjunctivitis. Am J Ophthalmol 1972; 74: 81-8.

9 Travers JP, Patterson A. A controlled trial of adenine arabinoside and trifluorothymidine in herpetic keratitis. $J$ Int Med Res 1978; 6: 102-4.

10 McGill J, Tormey P, Walker CB. Comparative trial of acyclovir and adenine arabinoside in the treatment of herpes simplex corneal ulcers. Br J Ophthalmol 1981; 65: 610-3.

11 Poirier RH. Aqueous penetration characteristics of three antiviral compounds, trifluridine, ara-amp and acycloguanosine. Annual Meeting Ocular Microbiology and Immunology Group 1979; abstract 64.

12 Van der Meer JWM. Acyclovir in severe Herpes virus infection. Proceedings the International Acyclovir Symposium, Bethesda September 1981. Am J Med suppl: in press. 